\title{
La ciencia de La Dorotea: apuntes de poética a la luz del "Prólogo al Teatro"
}

The Science of La Dorotea: Notes of Poetics in the light of the "Prólogo al Teatro"

\section{Patricia Festini}

Instituto de Filologia y Literaturas Hispánicas "Dr. Amado Alonso" Universidad de Buenos Aires, Argentina pfestini@gmx.net

\section{Resumen:}

El presente trabajo ofrece una lectura de algunas escenas de La Dorotea a la luz del "Prólogo al Teatro". A partir de la consideración de la poesía como ciencia, se intenta establecer una serie de relaciones con el eje historia/poesía que permite, por un lado, deslindar ciertas cuestiones de poética en torno a la "acción en prosa" de La Dorotea, y por otro, comprobar las múltiples coincidencias que estas cuestiones presentan con las propuestas en las Novelas a Marcia Leonarda, lo que permite acercar algunos episodios de $L a$ Dorotea al género novela corta.

Palabras Clave: Lope de Vega, La Dorotea, Novelas a Marcia Leonarda, Poética.

\section{Abstract:}

This paper offers a reading of some scenes from La Dorotea in the light of the "Preface to the Theatre". Based on the consideration of poetry as a science, it is intended to develop a series of relations with the focus on history/poetry which makes possible, on the one hand, to define certain issues of Poetics about the "action in prose" of La Dorotea, and on the other hand, to confirm the multiple coincidences that these issues present with those proposed in Novelas a Marcia Leonarda, bringing some episodes of $L a$ Dorotea closer to the short story genre.

KeYwords: Lope de Vega, La Dorotea, Novelas a Marcia Leonarda, Poetics.

Uno de los pasajes de La Dorotea más frecuentados por la crítica es esa suerte de academia que tiene lugar en las escenas segunda y tercera del acto IV, sobre todo, por su significación dentro de la polémica antigongorina. Pero, como siempre en Lope, el pasaje ofrece múltiples lecturas. Una de ellas es la posible relación que el contenido metaliterario de las escenas parece tener con el que Lope despliega en sus Novelas a Marcia Leonarda. En esta ocasión, quisiera rescatar el sintagma "hombres científicos" (2011a: 292) que en La Dorotea aparece en boca de Ludovico, el amigo poeta de don Fernando, para aludir, despectivamente, a aquellos que defienden la oscuridad en la poesía y que se refugian en la autoridad de esos hombres científicos para legitimar su postura. Unas líneas más adelante, el astrólogo César pretenderá insertar en su discurso “alguna cosa seria o científica” (2011a: 293), si viene a propósito del tema que están tratando. La conversación entre los dos amigos remite a las palabras liminares de Las fortunas de Diana, en las que el Lope narrador sugiere que los libros de novela, si bien son de gran entretenimiento y podrían ser ejemplares, "habían de escribirlos hombres científicos o por lo menos grandes cortesanos, gente que halla en los desengaños notables sentencias y aforismos" (2011b: 106).

Si bien, como ya he mencionado, la crítica se ha ocupado en gran medida de estas reflexiones metaliterarias, quisiera, en esta oportunidad, establecer otro juego de relaciones entre ambos fragmentos y, para eso, voy a detenerme, en principio, en el "Prólogo al Teatro" para, desde allí, tratar de proponer una lectura diferente de algunos momentos de La Dorotea.

El tan mentado prólogo se inicia con una clara referencia a la armonía del verso para confrontarlo, en cierto modo, con la prosa de la "Acción en prosa" que reza el subtítulo:

(...) puede asimismo el poeta usar de su argumento sin verso, discurriendo por algunas decentes semejanzas; porque esta manera de pies y números son en el arte poética como la hermosura en la juventud y las galas en la disposición de los cuerpos bien proporcionados, que el ornamento de la armonía está allí como accidente y no como real sustancia. 
De suerte que si alguno pensase que consistía en los números y consonancias, negaría que fuese ciencia la poesía. $L a$ Dorotea de Lope lo es, aunque escrita en prosa, porque siendo tan cierta imitación de la verdad, le pareció que no lo sería hablando las personas en verso como las demás que ha escrito; si bien ha puesto algunos que ellas refieren, porque descanse quien leyere en ellos de la continuación de la prosa, y porque no le falte a La Dorotea la variedad, con el deseo de que salga hermosa, (...) (2011a: 7-8)

Son varios los elementos a tener en cuenta en relación con este párrafo del "Prólogo al Teatro". En principio, la mención a la poesía. No es este el lugar para desarrollar una extensa digresión teórica sobre el tema, digresión que bien podría estar emparentada con las muchas que recorren las narraciones de Lope, a las que bautiza como intercolunios, y que fueron analizadas por Antonio Sánchez Jiménez (2013) en un artículo reciente. Simplemente, quiero rescatar esa significación de poesía que, a partir de Aristóteles, en consonancia con la teoría de la imitación, y a través de los tratadistas del Renacimiento, ${ }^{1}$ llega a los novelistas del siglo XVII fusionado con el concepto de fábula. ${ }^{2}$ La acción en prosa permite entender el término poesía en ese sentido e incluso jugar con el binomio aristotélico historia/poesía, ya que "el asunto fue historia" (2011a: 9). Historia que parece legitimarse por medio de la consideración de la poesía como ciencia, "siendo tan cierta imitación de la verdad" (2011a: 7-8). ${ }^{3}$

Y esto se consolida frente a la marcada diferenciación entre verso y poesía. Es común en los prólogos que encuadran las colecciones de novelas el anunciar que, para que no canse la prosa, se la mezcla con diferentes versos. Al respecto, pienso en Castillo Solórzano, un escritor muy cercano a Lope que, además, es el referente obligado frente a cualquier estudio de la novela corta post-cervantina. De hecho, presenta, en 1625, la primera de sus diez colecciones de novelas con un "seis novelas te presento adornadas con diferentes versos" (Preliminares sin foliar), tópico que se va a ir repitiendo a lo largo de su producción. ${ }^{4}$

Instalados, así, en el género novela corta, ya mencionamos que, desde las Novelas a Marcia Leonarda, Lope señalaba que a este tipo de relatos debían de escribirlos hombres científicos, gente que halla en los desengaños sentencias y aforismos. Y en La Dorotea, es el astrólogo César quien propone introducir cosas serias o científicas. Y lo propone en el centro de esas dos escenas que condensan las mayores líneas de reflexión metaliteraria de toda la obra. Aquellas que, en palabras de Carlos Brito Díaz, representan "la médula de la pieza" e incluyen "un sabroso escrutinio tanto de los «poetas desta edad» como de las prácticas filológicas al uso para iluminar un texto" (2009: 15).

A partir de todos estos elementos, quiero detenerme en una escena en las que la acción en prosa deja paso a la narración, ¿deja paso a una pequeña novela como aquellas escritas/contadas a Marcia Leonarda?

Me refiero a la escena con la que comienza el acto IV y que antecede, precisamente, al cenáculo literario formado por César, Ludovico y, posteriormente, Julio. El narrador es Fernando; los narratarios, Julio, Felipa y una embozada Dorotea, como una nueva Marcia Leonarda que escucha, en este caso, el relato de la historia de su amante y, por lo tanto, el relato de su propia historia.

"Yo, señoras, la que habla y la que no habla, nací de padres nobles en este lugar, a quien dejaron los suyos poca renta". (2011a: 255). Así comienza la narración de don Fernando, con una técnica muy común en la novela corta que Michel Moner (1986), refiriéndose a la narrativa cervantina, define como "relato curricular". Luego, presenta a Julio, como el ayo que lo acompañó cuando fue a estudiar a Alcalá lo que le permite introducir la primera "cosa científica o seria": "Para con tu doctrina, Julio, tengo por ignorante al Quirón de Aquiles. Pues por lo que toca a la verdadera amistad, ¡así fuera yo Alejandro como tú Efestión!”, a lo que Julio contesta: "No quiero responderte por no interrumpir el hilo de tu amorosa historia" (2011a: 256). La historia amorosa, la historia de amor de don Fernando, primero con Marfisa y luego con Dorotea, se desarrolla a lo largo de gran parte de la escena. Por supuesto, que con unos cuantos "intercolunios" y adornada con unos cuantos versos, "porque descanse quien leyere en ellos de la continuación de la prosa" (2011a: 8), como ya se nos había prometido en el prólogo.

Algunos elementos a destacar del extenso relato intercalado de don Fernando. En primer lugar, las numerosas digresiones y la inserción de versos, que acercan la narración a la propuesta de las Novelas a Marcia 
Leonarda. La historia se va engarzando con nombres, autoridades, cita de versos de otros poetas, tres romances escritos en torno de la imposibilidad de olvidar a Dorotea que anticipan una suerte de primer final de la "novelita", el momento en que don Fernando entierra el retrato de Dorotea, acompañado, por supuesto, de un soneto hecho a tal efecto.

Además, y en relación con los modos de narrar una novela corta en el marco de una estructura como la de La Dorotea, debemos destacar también la función de los interlocutores que contribuyen a consolidar el paradigma narrativo propuesto en las novelas publicadas en La Filomena y La Circe. Ya habíamos señalado la intervención de Julio sobre interrumpir el hilo de la historia. A ello, hay que sumarle la voz de Felipa en dos oportunidades: "Volved a engarzar la cadena de vuestro cuento, no se os pierdan algunos eslabones" (2011a: 257) o "Dejad historias, y venid a la vuestra" (2011a: 259), como un modo de equilibrar la narración frente a las digresiones de la voz narradora.

Pero el encuadre del relato está dado por el encuentro entre el par que forman Fernando y Julio frente a Felipa y Dorotea. Los hombres no conocen a Felipa, Dorotea está tapada, pero al finalizar la narración, ella no soporta más la situación y se muestra ante don Fernando. Aquí será la dama quien apele a la autoridad, ya que juega con la fábula de Hércules y Anteo para representar la lucha entre amor e interés, en la que ella sale derrotada a causa de la ausencia de don Fernando. La alegoría cobra mayor significación si tenemos en cuenta que el acto primero se cierra, luego del intento de suicidio de Dorotea, con el Coro de Amor; mientras que el segundo, en el que don Fernando no aparece ni una vez, porque está en Sevilla, finaliza con el Coro de Interés. Es posible percibir una vinculación entre la propuesta de los coros y los acontecimientos narrados en la historia intercalada que se corresponden temporalmente, junto con el relato ab initio de don Fernando, con los dos primeros actos de La Dorotea.

Finalizada esta escena, los amantes vuelven a unirse mientras los lectores asistimos al ya mencionado cenáculo literario. En este sentido, no solo es una novela intercalada sino una novela con final feliz. En la escena cuarta del cuarto acto, un muy alegre Fernando se une al debate literario luego de haber consumado el regreso a sus amores con Dorotea.

La extensa narración que don Fernando hace en esa primera escena del acto cuarto propone el desarrollo de un hilo narrativo dentro de la estructura y el contenido in mediasres de la acción en prosa. El lector repone así elementos importantes en la historia de los amantes. Pero la obra presenta otros momentos semejantes en los cuales, a través de la voz de uno de los personajes, es posible completar ese hilo narrativo que nos va a llevar al final de la historia de don Fernando, Marfisa y Dorotea.

Uno de ellos se ubica en la escena tercera del acto V. Allí, César y Julio asisten al relato de lo que podríamos llamar un nuevo capítulo de los amores entre Fernando y Dorotea, aunque, en este caso, la narración está mucho más contaminada por el diálogo que la que acabamos de analizar, sobre todo, por la presencia del astrólogo que no pierde la oportunidad de intervenir con "alguna cosa seria o científica". Si la comparamos con nuestro ejemplo anterior, se da, a lo largo de la escena, la construcción de una novela a dos voces, donde la mayoría de las digresiones están en boca del personaje sabio, mientras el protagonista va hilvanando la historia.

El punto de partida es el encuentro de ambos amantes: "Ya supistes, señor César, (...) lo que os referí a vos y a Ludovico que me había sucedido en el Prado una mañana de abril pasado con Dorotea" (2011a: 353-354). El nudo del relato es el fin del amor de don Fernando:

(...) Apenas, César, conocí que Dorotea me tenía el mismo amor que antes que me partiese a Sevilla, cuando comenzó mi espíritu a sosegarse, mi corazón a suspenderse, y todas las acciones de hombre cuerdo y prudente volvieron a la patria del entendimiento, de donde las había desterrado la inquietud de imaginarme aborrecido. (...) Al paso, finalmente, que Dorotea me iba descubriendo su pecho, iba yo sosegando el mío, y como se abrasaba en mis brazos de aquellos antiguos deseos, yo me helaba en los suyos. (2011a: 354)

Luego de esto, y con unas cuantas intervenciones, sobre todo del astrólogo, Fernando retoma la historia de sus amores. Entra en escena Marfisa, con otro salto hacia ese pasado no contemplado por la acción en prosa. 
Se refiere a los celos provocados por la presencia de don Bela, al intercambio de billetes amorosos a través de la reja, con hábito de pobre, y cómo, a partir de una camisa que Marfisa le regala, como en una comedia de enredo, se truecan los papeles y Dorotea conoce que ya no es la única en el corazón de don Fernando.

Como en la "novelita" del acto cuarto, hay referencias metatextuales en relación con las digresiones: una de César, "Prosigue el suceso, y perdona el haberte divertido" (2011a: 360), y otra de don Fernando, introduciendo el conflicto de la camisa, que nos vuelve a remitir al Lope narrador de Marcia Leonarda, y que pasa de la digresión a la auctoritas, casi sin avanzar en el relato:

Pero volviendo desta digresión a la historia -que ninguna deja de tener sus episodios, ni se ofende la buena retórica como no sean largos-, sabed César, que Marfisa tuvo gusto de hacerme una camisa, que fue como aquella de la hermosa Deyanira con la sangre del Centauro, aunque faltó en mi suceso la imitación de Alcides. (2011a: 361)

También aquí, el contenido de la narración corre casi en paralelo con la temporalidad de dos actos, esta vez, el tercero y el cuarto, cuyo final coincide con la confesión de Fernando de que solo tenía celos de Dorotea por su relación con don Bela, que ya no la amaba y que vuelve a fijarse en Marfisa. Incluso, aunque no tan explícitamente como en el ejemplo anterior, en el que el amor y el interés eran mencionados por Dorotea, encontramos aquí aludidos los celos y la venganza, en una posible correlación con el Coro de Celos, con que finaliza el acto tercero, y el de Venganza, con que concluye el cuarto. Los celos están implícitos en el proceso de alejamiento de don Fernando; celos que se transmiten a don Bela y que motivan el intercambio de papeles que va a acelerar el fin de la relación amorosa. A su vez, el tópico de la venganza atraviesa la escena. Ya desde el inicio, Fernando le pregunta a Julio si vengarse es amor. Este le responde que no, que es desesperación amorosa, con lo que el galán recita el romance que comienza "Si tuvieras, aldeana, ..." (2011a: 350) en el que se mezclan celos y venganza. En su diálogo con César, señala que determinó tomar venganza de la libertad de Dorotea y, por último, refiriéndose a la confusión de papeles que precipitó la ruptura, da gracias a la fortuna que por tan extraño camino llegó la venganza.

Con esta narración, puesta en la voz del protagonista, se reafirma aquella sentencia del prólogo de que "el asunto fue historia". Dice don Fernando, en una de sus muchas interrupciones, "perdone la fábula, pues por su gusto en esta ocasión se casó con la historia" (2011:354), aunque esa historia casada con la fábula podría concluir en el futuro que predice el astrólogo César en la escena octava del último acto:

Cés. Vos, don Fernando, seréis notablemente perseguido de Dorotea y de su madre en la cárcel, donde os ha de tener preso. El fin desta prisión os promete destierro del reino, poco antes de lo cual serviréis a una doncella que se ha de inclinar a vuestra fama y persona, con quien os casaréis con poco gusto de vuestros deudos y los suyos. Esta acompañará vuestros destierros y cuidados con gran lealtad y ánimo, para toda adversidad constante. Morirá a siete años deste suceso, y con excesivo sentimiento vuestro daréis vuelta a la Corte, viuda ya Dorotea, que os solicitará para marido. Pero no saldrá con ello, porque podrá más que su riqueza vuestra honra, y que sus amores y caricias vuestra venganza. (2011a: 385)

(...)

Cés. Marfisa se casará con hombre de letras segunda vez, que con un honroso oficio saldrá fuera destos reinos. Enviudará presto, y casándose con un soldado de nuestra patria, será muy desdichada.

Fer. ¿De qué forma?

Cés. Que la ha de matar de celos de un amigo suyo. (2011a: 387)

En medio de todos los vaticinios de César, don Fernando recuerda que "dice una ley que cuando la verdad y la ficción concurren juntas -y aunque no lo dijera- se ha de guardar a la verdad el decoro que de derecho divino y humano se le debe" (2011a: 386). Ya casi al final de la acción en prosa, la autobiografía se mezcla con la fábula en los presagios de un astrólogo. La verdad y la ficción confluyen en un futuro incierto porque es el mismo César quien le aconseja "que os portéis de suerte que se den por vencidas vuestras estrellas de la virtud de vuestro albedrío, contra el cual ninguna cosa es fuerte sino él mismo” (2011a: 386), en clara consonancia con el Coro del Ejemplo con que concluye la obra. 
El "Prólogo al Teatro" afirmaba que La Dorotea era ciencia. Ciencia en prosa, poesía en prosa, fiel a su imitación de la verdad. Y la verdad también disculpaba algún defecto que su arte tuviera, “(...) que más quiso el poeta seguirla que estrecharse a las impertinentes leyes de la fábula. Porque el asunto fue historia” (2011a: 9).

A partir de esta historia casada con la fábula (o la fábula casada con la historia) fue posible extraer la historia de don Fernando, narrada por él, como un nuevo Lope, y por César, el hombre científico, aquel que halla en los desengaños notables sentencias y aforismos, aquel que puede lograr que las novelas sean ejemplares.

El Prólogo también nos recuerda que "el papel es más libre teatro" para contar este tipo de historias, y que nos parecerán vivos "los afectos de dos amantes, la codicia y trazas de una tercera, la hipocresía de una madre interesable, la pretensión de un rico", etc., etc.; "y para el justo ejemplo, la fatiga de todos en la diversidad de sus pensamientos, porque conozcan los que aman con el apetito y no con la razón, qué fin tiene la vanidad de sus deleites y la vilísima ocupación de sus engaños". (2011a: 8)

El justo ejemplo corona la presentación que de La Dorotea se hace en el prólogo. La literatura ejemplar parece manifestarse en la escena de los presagios de César, al interponer a los avatares de la fortuna el libre albedrío. No por nada el hombre científico incita a don Fernando a leer el capítulo séptimo del libro de los Proverbios, aquel que condena el amor vicioso que lleva a la muerte.

La novela interpolada en la acción en prosa es, entonces, una novela ejemplar. Hasta esa intervención de la fama en la escena última parece confirmarlo:

esta es La Dorotea, este fin tuvieron don Bela, Marfisa y Gerarda, Lo que resta fueron trabajos de don Fernando. No quiso el poeta faltar a la verdad, porque lo fue la historia. Si ha cumplido con el nombre, advertid el ejemplo a cuyo efecto se ha escrito. (2011a: 401)

De este modo, desde el final, se valida la ciencia ejemplar de La Dorotea. Ejemplar, no en el sentido moral (o no solo en el sentido moral). Ejemplar en su arte, ya viejo, de hacer novelas que propone una ciencia de la poesía, una ciencia de la escritura, una ciencia que tan bien maneja la pluma de Lope en la que todo confluye en el delicado equilibrio de la narración de la fábula, todo en su justa medida. Tanto es así que la estrofa final del Coro del Ejemplo es un pequeño tratado que resume los modos de escritura que dieron vida a su última travesura literaria:

\author{
Cuando del amor lascivo \\ El trágico fin contemplo, \\ No solo al deleite escribo, \\ Pero sentencioso templo \\ La doctrina en lo festivo, \\ $Y$ en el engaño el ejemplo. (2011a: 402)
}

\title{
Bibliografía
}

Brito Díaz, Carlos, 2009. "Burlas y veras de Lope: La Dorotea como escrutinio”, Anuario Lope de Vega, XV, 11-18. Castillo Solórzano, Alonso, 1625. Tardes entretenidas, Madrid: por la viuda de Alonso Martín, a costa de Alonso Pérez. Castillo Solórzano, Alonso, 1977. Sala de recreación, R. Glenn y F. Very (eds.), Chapel Hill: Estudios de Hispanófila. López Pinciano, Alonso, 1596. Philosophía Antigua Poética, Madrid: por Thomas Iunti.

López Pinciano, Alonso, 1953. Philosophía Antigua Poética, A. Carballo Picazo (ed.), Madrid: C.S.I.C., 3 vols.

Lugo y Dávila, Francisco, 1622. Teatro popular: novelas morales para mostrar los géneros de vidas del pueblo, y afectos, costumbres, y pasiones del ánimo, con aprovechamiento para todas las personas, Madrid: por la Viuda de Fernando Correa Montenegro.

Moner, Michel, 1986. "El 'relato curricular': algunos aspectos de la narrativa cervantina”, en Y. Fonquerne y A. Egido (coords.), Formas breves del relato, Zaragoza: Universidad, 167-176. 
Sánchez Jiménez, Antonio, 2013. "La poética de la interrupción en las Novelas a Marcia Leonarda, en el proyecto narrativo de Lope de Vega”, en Ficciones en la ficción. Poéticas de la narración inserta (siglos XV-XVII), V. Núñez Rivera (ed.), Barcelona: Studia Aurea Monográfica, 4, Universidad Autónoma de Barcelona, 99-114.

Vega, Lope de, 2011a. La Dorotea, D. McGrady (ed.), Madrid: RAE.

Vega, Lope de, 2011b. Novelas a Marcia Leonarda, A. Carreño (ed.), Madrid: Cátedra.

Vega, Lope de, 2012. Arcadia, prosas y versos, A. Sánchez Jiménez (ed.), Madrid: Cátedra.

Weinberg, Bernard, 2003. Estudios de Poética clasicista, Madrid: Arco/Libros.

\section{Notas}

1 A modo de ejemplo, podemos recordar las palabras de Robortello cuando se pregunta "¿qué otro objetivo diríamos que tiene el arte de la poesía si no es el de proporcionar placer por medio de la representación, la descripción y la imitación de todas las acciones humanas (...)?" (apudWeinberg, 2003: 66); o las del Pinciano, cuando señala que la "Poesía no es otra cosa que arte que enseña a imitar con la lengua, y poema es imitación hecha con la dicha lengua y lenguaje” (1596: 101). Cito por la edición original, porque hay un error de transcripción en la edición de Alfredo Carballo Picazo, por lo que el fragmento no está completo (cfr.: 1953: 195).

2 En el marco narrativo de Teatro popular,una de las colecciones de novela de aparición muy cercana a las Novelas a Marcia Leonarda, Francisco Lugo y Dávila pone en boca de uno de sus personajes la definición de "fábula" como punto de partida para la narración de las novelas que formarán parte del entretenimiento concertado en el encuadre: "La definición verdadera, y que hace a nuestro propósito, es cogida de Aristóteles, en su Poética, y a mi ver, quiditativa, a este género de fábulas, propia a las novelas. Esta fábula es imitación de la acción, y no dijo de las acciones, porque no le es permitido a la novela abrazar más que una acción, así como la tragedia” (1622: f. 3v).

3 Ya en el libro V de la Arcadia (1598), encontramos una primera reflexión sobre el par historia-poesía en el recorrido por las artes liberales en el que se ve "el efeto que hace la ciencia" (2012: 584). Allí, la poesía prevalece sobre la historia, como se desprende de las octavas que oyen los pastores en su palacio: "Canto las armas, el furor y espanto, / el tierno amor, los hechos valerosos, / que no puede decir la historia tanto, / vencida de mis versos numerosos” (2012: 634).

4 La mención a la inserción de versos en la prosa va a ser un tema recurrente en los prólogos de Castillo Solórzano, desde la primera a la última de sus colecciones, como puede observarse en el prólogo al lector de Sala de recreación (1649): “(...) Lo moral que hallares en estas Novelas, basta para muchos advertimientos; este ha sido mi fin, y para que no canse la prosa, lo mezclo con diferentes versos y Saraos entretenidos, todo a fin de entretenerte. (...)” (1977: 42). 